\title{
THE GENETICS OF CONGENITAL HEART DISEASE AND SITUS INVERSUS IN SIBS
}

\author{
BY \\ MAURICE CAMPBELL \\ From the Cardiac Department, Guy's Hospital, and the Institute of Cardiology \\ Received June 21, 1958
}

There have been many reports of the same or similar congenital malformations of the heart in two sibs or in a child and parent. Abbott (1927) found 11 such pairs and Brown (1939) who had seen six pairs thought they were most common in members of the same generation. Medvei and Rösler (1932) collected 37 families with such pairs and Gänsslen et al. (1940) 68 families: the diagnoses made at that time can not now be accepted as certain without necropsy proof and this was available only in a minority. Campbell (1949) reported four pairs and mentioned some others more briefly. Since then several have been reported and a great many have been seen.

However, few large series have been reported, so our 40 families seem worth recording. Of these pairs, 26 were sibs, 9 were parent and child, and 6 were less close relatives, one family (F26) being included in both the first groups, as a woman and her son were certainly affected and probably her brother and her father. There were six other families with more than two members affectedthree sibs in four (F3, 6, 11, and 35), an uncle as well as two sibs in one (F8), and a grandmother as well as a mother and daughter in one (F34). There was less decisive evidence of a third member being affected in two others (F26 and 29). Generally the malformations found were the same or similar in both members of the pair (concordant) but sometimes they were quite different (discordant).

It is important for a clinician to emphasize that it is not very common for two children with congenital heart disease to be born in one family. The parents of a child with a congenital malformation should not be deterred from having another child by the fear that it will be abnormal for this is not very likely. It is certainly more likely than would be expected by chance, but these 40 exceptions have been found among about 2000 families with a case of congenital heart disease-an incidence of 2 per cent.

Polani and Campbell (1955) made a statistical enquiry into the families of 396 patients, mostly with Fallot's tetralogy, and found the incidence of congenital heart disease among the sibs born after the propositus was between seven and twenty times as large as would be expected by chancetwenty times as large, 2 per 100 instead of 1 per 1000, taking the number who were alive at the age of ten years, or seven times as large taking the figure that includes all children born alive with congenital heart disease.

In eight of their patients where a sib also had congenital heart disease, six had Fallot's tetralogy, the seventh was thought to have pulmonary atresia, and the eighth had arachnodactyly. Three of the sibs died in the first few months of life, so all we know is that they were cyanotic and were said to have congenital heart disease, but we have fuller details about the other five-Cases O185, P021, P028, CB11, and P215 of their Table 12-and these are included as Families 1, 6, 11, 19, and 22.

Polani and Campbell reported 25 other examples of congenital heart disease among parents or relatives but could draw less valid conclusions about the incidence, as the number of relatives at risk was not known. We have little to add about these 25 secondary cases because few of them were examined by us and generally all we knew is that they were said to have had congenital heart disease and often died within a few days or months. Even in others where we have obtained information from the doctor it was not often possible to make a diagnosis. For example, an uncle of a girl with Fallot's tetralogy, who had a systolic murmur and 
moderate disability from infancy and a large heart, died with congestive heart failure when he was 20 , but there was no necropsy. In another, the first cousin of a young man with coarctation of the aorta had a systolic murmur from birth and died from hæmorrhage when 25 , but this turned out to be uterine, not cerebral hæmorrhage.

In 3 of the 25 pairs, however, we have fuller details, and Cases P107, O015, and O255 of their Table 20 are included as Families 5, 15, and 20. The fact that only three are included in this paper shows that our numbers could be larger, but it seemed more useful to confine it in the main to pairs where we know the nature of the heart disease in both of the pair, though not always as fully as we would wish.

It has not been easy to decide how to present these families. Most of the cyanotic cases were included in the first four groups. In Families 1-8 both members of the pair were cyanotic. In Families 10-19 one was cyanotic and one was acyanotic, but the discordance was not complete for often both the pair had pulmonary stenosis, the cyanotic one having a ventricular septal defect and the acyanotic one being without this. In the larger half both members of the pair were acyanotic (F 9 and F 20-40). The only exceptions here were some patients with pulmonary stenosis who had been acyanotic but had become cyanotic from a right-to-left shunt through an unsealed foramen ovale. Whether they are acyanotic or cyanotic depends on the stage at which they are seen, and Campbell (1954) has suggested that for most purposes these two forms should be considered together because of their close similarities. They were classified as follows.

Group I. (Families 1-5). Both members of the pair cyanotic.

Group II. (F 6-10). One or both members of the pair with situs inversus. These have been grouped together because of what is known about its inheritance. In some it was the sole abnormality, but most others had cyanotic heart disease, and Families 6-8 might have been included in the first group.

Group III. (F 11-15). Pairs where one member had Fallot's tetralogy and the other had one of its main components, pulmonary stenosis or a ventricular septal defect or both.

Group IV. (F 16-19). The members of the pair discordant with different types of heart disease, one being cyanotic and one acyanotic.

Group V. (F 20-21). The members of the pair discordant, but both acyanotic.

Group VI. (F 22-40). Both members of the pair acyanotic and concordant, with lesions that were proved or seemed to be the same or very similar. This is much the largest group.

\section{CASE Notes}

For those who do not like reading case notes, Families 1, 5, 6, 8, 11, 17, 23, 26, 30, 33, and 40 will give a good general picture. In the notes that follow, the first member mentioned is the one who brought the family under observation.

PNR indicates that special enquiries had been made and that, as far as they knew, the Parents were Not Related. Generally this included an answer that the respective grandparents were not related.

NORCD indicates that special enquiries revealed No Other Relations with Congenital Disease, either of the heart or elsewhere, apart from those mentioned.

* denotes that the diagnosis was firmly established, often with necropsy or operation, in at least one member of the pair.

** denotes that this was so for two members of the pair.

I. Both Members of the Pair Cyanotic (5 Families)

*Family 1. PNR. NORCD. Two brothers with Fallot's Tetralogy. The younger had classical Fallot's tetralogy: He had never worked and could not walk 400 yards. When 19, he had infundibular resection and 8 years later is in excellent health. His elder brother died at the age of 9 and was said to have been the same in every way, i.e. cyanotic, disabled, and a squatter. They had one sister who was normal.

*Family 2. PNR. NORCD. Two sisters, one with Fallot's Tetralogy and one with Morbus Caruleus. The younger sister died when 9 months old with left lateral sinus thrombosis following bilateral otitis media: necropsy confirmed the diagnosis of Fallot's tetralogy. The elder sister was cyanotic from birth and died when 11 days old with morbus cœruleus. There were no other sibs. 
*Family 3. PNR. NORCD. Three sibs with Morbus Coruleus. A girl, aged 4, was thought to have Fallot's tetralogy though there was little cyanosis: three years later she was better and even less cyanosed, and a ventricular septal defect seemed more likely. A younger brother had severe cyanosis that had been present from birth, and also spina bifida and a club foot: he died when 7 weeks old. A younger sister was seen when she was one, with moderate cyanosis, a diminished blood flow to the lungs, and signs suggestive of pulmonary atresia rather than uncomplicated Fallot's tetralogy: she died six months later with a cerebral abscess and bronchopneumonia, but there was no necropsy. These were the fourth, sixth, and seventh children, the first three and the fifth being normal.

*Family 4. PNR. NORCD. Woman with Pulmonary Stenosis and a right-to-left inter-atrial shunt, and cousin with Morbus Coruleus. A woman, aged 26, had classical signs of pulmonary stenosis and was well till she was 18 , after which she became increasingly cyanotic and disabled. Nine years after pulmonary valvotomy she is acyanotic and in excellent health. Her paternal cousin had died with congenital heart disease when she was 21 and was said to be cyanotic. Our patient had very extensive brown patches without leucodermia over her skin and her sister's child had the same condition. This sister was the only other sib in the family.

**Family 5. PNR. NORCD. Two boys, children of first cousins, both with Fallot's Tetralogy and both dying suddenly. The first, an only son, was cyanosed from birth and squatted. He was thought to have Fallot's tetralogy or pulmonary atresia, as there was triple rhythm and an insignificant systolic murmur, but less right ventricular preponderance than usual. Up to the age of six he had several cyanotic attacks in which he went unconscious, but none after this till his death. He declined operation, but two years later at the age of 19 , died absolutely suddenly.

The second, the middle of three children, his brother and sister being normal, was also cyanotic from birth, but squatted less often. When 6 , he was thought to have Fallot's tetralogy with some complication as his heart was larger than usual (c.t.r. $60 \%$ ). Catheterization a year later confirmed a valvular stenosis and a right-to-left shunt through an atrial septal defect, probably with a ventricular septal defect as well. Unfortunately his heart stopped and in spite of immediate thoracotomy and valvotomy he died. Necropsy confirmed that both septal defects were large. The mothers of these two children were first cousins.

\section{One Member of the Pair at least with Situs Inversus (5 Families)}

**Family 6. PNR. NORCD. Two sibs with Morbus Coruleus and a third with Situs Inversus. A girl, aged 8 , was severely cyanosed and disabled, and was thought to have pulmonary atresia with a persistent ductus or a large bronchial artery to the right lung. After a left subclavian-pulmonary anastomosis, she could lead a normal life and has kept well for nine years. Her sister, born two years later in 1941, died within an hour of birth.

Her brother, born in 1943, was cyanotic and died after four months with a "hole in the heart". In 1949 her mother had a miscarriage at four months and in 1954 she gave birth to a daughter with complete situs inversus. Her mother looked very healthy but her younger sister was a cretin, now aged 35, and a third sib died after a month and was said to have been a blue baby.

${ }^{* *}$ Family 7. NORCD. Two first cousins with Morbus Caruleus, one (Parents first cousins) with Situs Inversus and the other (PNR) with Inversion of the Abdominal Viscera (fully reported by Campbell and MacCarthy, 1957). The first, an only child whose parents were cousins, was moderately disabled when four years old: he had situs inversus and investigations suggested a very large ventricular septal defect and pulmonary stenosis, with a general picture like Fallot's tetralogy. The mothers of this boy and of the second case were sisters.

The second, a girl, died when five months old, and necropsy showed transposition of the abdominal viscera, transposed atria, a single ventricle, and tricuspid and pulmonary atresia. Her elder sister was normal.

**Family 8. PNR. NORCD. Boy with Fallot's Tetralogy and Situs Inversus, sister with Situs Inversus, and uncle with Morbus Ceruleus. A boy of 5 had situs inversus and probably Fallot's tetralogy. His sister had situs inversus with a normal heart and there were two other normal sibs.

His mother's parents were first cousins, the children of twins, probably identical twins. There were congenital abnormalities on the father's side as well, for the father's brother was diagnosed as having Fallot's tetralogy at the age of 4 years. When he died at the age of 32, necropsy showed a small left ventricle that had no exit except through a high ventricular septal defect, and a large aorta arising from the large right ventricle. There was no sign of pulmonary trunk and the lungs were supplied through large bronchial arteries. His heart and abdominal viscera were not transposed.

**Family 9. PNR. NORCD. Boy with Anomalous Pulmonary Venous Drainage and Situs Inversus and uncle with Situs Inversus. A man, aged 18, had situs inversus with a left-to-right shunt at atrial level: at least two pulmonary veins from the left lung drained into the venous (left) atrium. His mother's brother had situs inversus. The patient's mother and elder brother and the uncle's six sibs were all normal.

*Family 10.PNR. Girl with Pulmonary Atresia and Situs Inversus, and mother's cousin with Situs Inversus. 
A girl, aged 3, had situs inversus and was thought to have pulmonary atresia. When 8 , she had a subclavianpulmonary anastomosis and was much improved but died two years later with heart failure after subacute bacterial endocarditis. Her elder brother had an operation for pyloric stenosis in infancy, and her younger brother was normal. Their mother's cousin had situs inversus.

\section{Both the Pair with Pulmonary Stenosis, with or without a Ventricular Septal DEFECT (5 FAMILIES)}

**Family 11. PNR. NORCD. Boy with Fallot's Tetralogy and brother (and probably sister) with simple Pulmonary Stenosis. A boy, aged 7, was an example of severe Fallot's tetralogy, perhaps with pulmonary atresia: he had a larger heart than usual, a hæmoglobin of 150 per cent, and right bundle-branch block. He lived for another five years-much longer than was expected.

His brother, who was said to have aortic stenosis, was seen seven years later, when he was 23 , and had, in fact, severe pulmonary valvular stenosis with a closed ventricular septum, the pressure being 112/14 in the right ventricle and $22 / 5 \mathrm{~mm}$. in the pulmonary trunk. Valvotomy has been advised. It has not been possible to examine the sister, but as both were said to have aortic stenosis, one certainly wrongly, it seems more likely that she too has pulmonary stenosis. A fourth sib, a girl, is normal.

**Family 12. PNR. NORCD. Man with Fallot's Tetralogy and sister with simple Pulmonary Stenosis. A man, aged 22, with Fallot's tetralogy had been breathless and cyanosed since infancy and could rarely walk a hundred yards. After infundibular resection he was much improved, and two years later he was acyanotic and could walk a mile with comfort.

His sister, aged 11, was found at school to have a systolic murmur; she was acyanotic and had only slight dyspnœa playing games. She had pulmonary valvular stenosis with a closed ventricular septum, the pressures being $80 / 0$ in the right ventricle and $8 / 3 \mathrm{~mm}$. Hg in the pulmonary trunk. Operation was not advised and at 14 she is still well. These two were the second and seventh of eight sibs, six girls and two boys, all the others being normal.

*Family 13. PNR. NORCD. Boy with Pulmonary Stenosis and brother probably with Fallot's Tetralogy. A boy, aged 3, had signs of pulmonary valvular stenosis with right ventricular preponderance; three years later he was still without symptoms. He had, then, a brother three months old who was cyanotic with a loud systolic murmur and was thought to have Fallot's tetralogy. There are not yet any other sibs. The mother's uncle died when three years old with a congenital spinal defect.

**Family 14. PNR. Boy with Pulmonary Stenosis and V.S.D.; brother with Fallot's Tetralogy. A boy, aged 8 , had never been cyanotic and was found to have a ventricular septal defect with a left-to-right shunt of moderate size, slight pulmonary stenosis, and an aneurysmal right pulmonary artery. A younger brother, aged 5, who had been cyanotic from birth, was breathless and squatted frequently: he was thought to have Fallot's tetralogy. There was one normal sister. I am indebted to Dr. Paul Wood for asking me to see this pair.

**Family 15. PNR. NORCD. Boy with Fallot's Tetralogy and aunt with Ventricular Septal Defect. A boy, aged 19, had classical Fallot's tetralogy and was greatly improved by a subclavian-pulmonary anastomosis. Two years later he had a successful operation for a left temporal lobe abscess. He worked as an engineer and remained well until the tenth year when he died from a second cerebral abscess. He had four sibs who were normal.

His mother's sister had a ventricular septal defect but was able to do domestic work till she was over 40 . When 43 , the pressure in the two circuits were almost balanced (pulmonary 128/56; systemic 120/65) and she had a left-to-right shunt of 3.5 litres and a right-to-left shunt of 0.8 litres a minute. She died two years later.

\section{Pairs that are Discordant, one Member Cyanotic and one Acyanotic (4 Families)}

*Family 16. PNR. NORCD. Boy with Aorto-Pulmonary Fistula and brother with Fallot's Tetralogy. A boy, aged 6, had few symptoms but signs suggestive of a persistent ductus, though an aorto-pulmonary fistula was thought more likely: his heart was enlarged (c.t.r. $54 \%$ ) and his blood pressure averaged $123 / 29$. He has remained much the same for six years and every effort to persuade his parents to allow catheterization has failed.

A brother born four years later died in his second year. We are indebted to Dr. Harrison, who had reported his recovery from subacute bacterial endocarditis (Harrison, 1948), for an account of his necropsy and for letting us see the heart, which was a characteristic example of Fallot's tetralogy. The eldest sib, a girl, was normal.

**Family 17. Man with Fallot's Tetralogy and son with Persistent Ductus. A boy, aged 14, had Fallot's tetralogy with moderate disability and cyanosis. He had subclavian-pulmonary anastomosis in 1947 and ten years later was very well, working full-time and leading a normal quiet life in New Zealand. He was married and had three children, and one of these had a persistent ductus that had been closed successfully. So far as we know, this is the only child with congenital heart disease born to any of our patients who have had an operation for Fallot's tetralogy, but the number who have married is still small. 
*Family 18. PNR. NORCD. Girl with Fallot's Tetralogy and mother with Atrial Septal Defect. A girl, aged 24, died after valvotomy and the diagnosis of Fallot's tetralogy was confirmed at necropsy. A younger brother and sister were normal. Her mother who had died when her youngest child was born was said to have had an atrial septal defect.

*Family 19. PNR. NORCD. Woman with Fallot's Tetralogy and brother with Congenital Heart Disease. A woman, aged 21, had a very successful infundibular resection for Fallot's tetralogy and has done well for eight years. Her next sister was normal. Her youngest sib, a brother, died with congestive heart failure due to congenital heart disease when ten weeks old: this was confirmed by necropsy, though I have been unable to get details. They are included as a cyanotic and acyanotic pair since death from congestive heart failure so early is more often due to a large left-to-right shunt.

\section{Pairs that are Discordant but both Members Acyanotic (2 Families)}

**Family 20. PNR. NORCD. Girl with Coarctation and mother with a Persistent Ductus. A girl, aged 8, had a blood pressure of $160 / 110$ in the arms, no palpable femoral pulse, a collateral circulation in the back, and notching of the ribs. Her condition has not changed during eight years observation without having an operation. Her elder only brother was normal.

Her mother, aged 31, was well but had not played games at school because of a murmur. She has a soft continuous murmur under the left clavicle that is characteristic of persistent ductus, with a systolic thrill. The murmur had almost certainly been louder when she was a girl or it would hardly have been recognized.

*Family 21. PNR. NORCD. Girl with Persistent Ductus and mother with Pulmonary Stenosis. A girl, aged 3 , had a persistent ductus and this was closed successfully. Her only and elder brother was normal. Her mother had not played games at school because of congenital heart disease; she had been told that she might grow out of it, but it seems unlikely that the doctor successfully foretold the closing of a ductus. She has a harsh systolic murmur in the pulmonary area, a prominent pulmonary arc, and a slightly enlarged heart, so was thought to have slight pulmonary valvular stenosis.

\section{Pairs that are Concordant and Acyanotic (19 Families)}

**Family 22. PNR. NORCD. Two sisters with Arachnodactyly and Heart Disease. A girl, aged 19, had arachnodactyly with spider fingers, chondro-osteo-dystrophic changes in the spine, subluxation of each lens, and a harsh systolic murmur. She developed aortic regurgitation and later congestive heart failure from which she died a year later.

Her sister, who had arachnodactyly with similar changes in the bones and eyes, and a systolic murmur, died suddenly when she was 17 after two "heart attacks". The third sib, a boy aged 4, was normal. These two, with an account of the necropsy of the first, have been fully reported by Reynolds (1950).

**Family 23. PNR. NORCD. Two sisters with Coarctation of the Aorta. A girl, aged 13, had coarctation with few symptoms but with a blood pressure that averaged 155/112 and some enlargement of the left ventricle (c.t.r. $55 \%$ ). After operation her pressure fell to $115 / 70 \mathrm{~mm}$.

Her mother, having overheard comments about the importance of pulsation in the neck in diagnosing coarctation, noticed this in her younger girl, aged 10, and brought her to hospital. The diagnosis was confirmed; the blood pressure was 175/137 and the heart enlarged (c.t.r. 56\%). Her operation was equally successful and the pressure fell to $115 / 75$. In both cases the heart became smaller and the left ventricular preponderance in the electrocardiogram disappeared. Although both these sisters had severe coarctation and extremely successful operations, they were not much alike. The elder was thin with a rather narrow chest, and the younger who had the higher pressure was sturdy with a broad chest: she had undergone an operation for congenital cataract early in life. The third sib, a brother, was normal.

**Family 24. PNR. NORCD. Two brothers with Aortic Stenosis. Both had systolic murmurs and thrills maximal in the aortic area. In both the left ventricle was full and rounded though there was no general enlargement of the heart. The younger, aged 8 years, played games without any symptoms. He showed left ventricular preponderance without any $\mathrm{T}$ wave inversion. Three years later he was equally well, but after finding the blood pressure was $125 / 60$, a long but faint diastolic murmur that had been missed at first was heard, so that aortic regurgitation had developed spontaneously.

The elder brother, aged 10, had had an operation for intussusception in his second year. He was more disabled and breathless and could not run much. His blood pressure was normal but the pulse was small and the left ventricular preponderance and strain were more severe than in his brother (see Table I). Two years later as his symptoms were increasing, aortic valvotomy was carried out. He felt better and the left ventricular strain almost disappeared, but unfortunately severe aortic regurgitation was produced and after a year his blood pressure was 130/42, and in the long term view this must become a serious handicap. There were no other sibs.

**Family 25. PNR. NORCD. Two sisters with Aortic Stenosis. A girl, aged 10, was found to have a systolic murmur in the aortic area when one year, and a thrill when five years old. She led an active life and had no symptoms until she was 9 when she became more aware of her heart which had become larger 
(c.t.r. $53 \%$ in $1954 ; 62 \%$ in 1957). Her blood pressure was $105 / 80$ and she had gross left ventricular strain (see Table I). At operation, the gradient was from 212/24 in the left ventricle to 90/70 in the aorta. This was greatly reduced by operation and six months later she was better.

Her elder sister, now 17, was known to have a murmur when 2, and was diagnosed aortic stenosis by Sir John Parkinson when she was 8 years old. When 9 she became very obese and her symptoms seemed due to this. She had, however, classical signs of aortic stenosis but without general enlargement of the heart or any effect on the pulse, the blood pressure being 130/90. Her cardiogram showed left ventricular preponderance but no strain. The eldest sister was normal.

${ }^{* *}$ Family 26. PNR. NORCD. Woman and son certainly, and her brother and father probably, with Aortic Stenosis. A woman, aged 51, knew that she had had a murmur when she was three years old, but had led a normal life without symptoms. She had been getting a little breathless on hills for six years but could still do most things. She had classical signs of aortic stenosis with some left ventricular strain. Her father and her elder brother were said to have the same sort of heart condition, but have not been examined. Her second brother and her only sister were normal.

TABLE I

Degree of Left Ventricular Preponderance in Patients with Congenital Aortic Stenosis

\begin{tabular}{|c|c|c|c|c|c|c|}
\hline $\begin{array}{l}\text { Family } \\
\text { No. }\end{array}$ & $\begin{array}{l}\text { Sex } \\
\text { and } \\
\text { age }\end{array}$ & $\begin{array}{l}\mathrm{S} \\
\text { in } \\
\mathrm{V} 1 \\
\mathrm{~mm}\end{array}$ & $\begin{array}{c}\mathrm{S} \\
\text { in } \\
\mathrm{V} 2 \\
\mathrm{~mm}\end{array}$ & $\begin{array}{l}\text { Largest } \mathrm{R} \\
\text { in } \\
\mathrm{V} 5 \text { or } \mathrm{V} 6 \\
\mathrm{~mm} .\end{array}$ & $\begin{array}{l}\text { Largest } \\
\stackrel{\mathrm{S}}{+} \\
\mathbf{R}\end{array}$ & $\begin{array}{c}\text { Leads in which } T \text { waves were } \\
\text { inverted }\end{array}$ \\
\hline 24 & $\begin{array}{l}\text { M8 } \\
\text { M10 } \\
13\end{array}$ & $\begin{array}{l}19 \\
43 \\
30\end{array}$ & $\begin{array}{l}27 \\
44 \\
30\end{array}$ & $\begin{array}{l}26 \\
47 \\
25\end{array}$ & $\begin{array}{l}53 \\
91 \\
55\end{array}$ & $\begin{array}{l}\text { None } \\
\text { I, V4, V5, V6 } \\
\text { (V6) only after operation }\end{array}$ \\
\hline 25 & $\begin{array}{l}\text { F } 10 \\
\text { F } 17\end{array}$ & $\begin{array}{l}36 \\
22\end{array}$ & $\begin{array}{l}46 \\
28\end{array}$ & $\begin{array}{l}60 \\
18\end{array}$ & $\begin{array}{r}106 \\
46\end{array}$ & $\begin{array}{l}\text { I, V4, V5, V6 } \\
\text { None: flat in I and V6 }\end{array}$ \\
\hline 26 & $\begin{array}{l}\text { M29 } \\
\text { F } 51\end{array}$ & $\begin{array}{l}20 \\
23\end{array}$ & $\begin{array}{l}30 \\
25\end{array}$ & $\begin{array}{l}17 \\
14\end{array}$ & $\begin{array}{l}47 \\
39\end{array}$ & $\begin{array}{l}\text { None: small in V5, V6 } \\
\mathrm{I} \text { : late rising in V5 and V6 }\end{array}$ \\
\hline
\end{tabular}

Her son had a murmur from early childhood and when he was 13 there was a rough systolic murmur at the base of the heart that had been attributed to a ventricular septal defect but aortic stenosis seems more likely. So I had written before I saw him when he was 29 . There was no doubt about the aortic stenosis. He had a rough systolic murmur and thrill in the aortic area and left ventricular preponderance without strain (see Table I). He was leading a normal life and played energetic squash. His only sister was normal.

${ }^{* *}$ Family 27. PNR. NORCD. Brother and sister with Pulmonary Valvular Stenosis. The boy, aged 8, was becoming more breathless and was cyanotic from a right-to-left shunt through an unsealed foramen ovale. The right ventricular pressure was $118 / 12 \mathrm{~mm}$. Hg. After pulmonary valvotomy he has remained in good health for seven years. A large nævus had been removed from his arm when he was a year old.

His sister, aged 2, had identical physical signs but few symptoms, no cyanosis, and no enlargement of the heart, so operation was not advised. When she was 7 she still seemed well but the heart had become large (c.t.r. $59 \%$ ) and the right ventricular strain was now severe with $\mathrm{T}$ inversion to V5. The pressure in the right ventricle was $170 / 5 \mathrm{~mm}$. Hg which was more than double the systemic pressure at that time and the arterial oxygen saturation was 90 per cent. (Her brother's had been 89 per cent). Operation was therefore advised and was carried out under hypothermia, but unfortunately the patient died. Necropsy confirmed the diagnosis of simple pulmonary valvular stenosis with an unsealed foramen ovale. The eldest child, a girl, was normal. All three children were born by Cæsarean section but this was due to the mother's narrow pelvis.

${ }^{*}$ Family 28. PNR. NORCD. Sister and probably brother with Pulmonary Stenosis and Ventricular Septal Defect. A girl, aged 9, had no symptoms but a harsh systolic murmur and thrill in the pulmonary area. The heart was enlarged (c.t.r. 58\%) including the left ventricle. There was right ventricular preponderance with T inversion in V1 and V2. The lungs were pleonæmic with a hilar dance, and a persistent ductus in addition to pulmonary stenosis was wrongly suspected, as the murmur in diastole was heard higher up than is usual for a functional murmur from a septal defect. Catheterization confirmed pulmonary stenosis with a gradient from $88 / 2$ to $15 / 10$ and a left-to-right shunt that was thought to be at ventricular level. The pulmonary flow was 6 litres and the systemic flow 3 litres a minute. In view of the combination of lesions no operation was advised. 
Her younger brother, aged 6, had similar physical signs, except that the diastolic murmur was softer and the heart was not enlarged. He too had right ventricular preponderance. It seems likely that he has the same combination of lesions, but all attempts to get him in for investigation have failed. Their elder brother was normal.

**Family 29. PNR. NORCD. Sister and brother with Persistent Ductus Arteriosus. In the sister a murmur was heard at nine months and was typical of a ductus at 3 years: when she was 6 there was already some enlargement of the left ventricle on radioscopy, and the ductus was ligated. The brother, who was then nine months old, had a rough systolic murmur in the pulmonary area that continued into early diastole. The lungs were pleonæmic, the left ventricle already slightly enlarged, and the pulse pressure wide for his age so that a persistent ductus seemed likely, and this was proved by successful ligation a year later. Their elder sister was normal, but the mother's sister had lost a girl 10 weeks old with congenital heart disease.

**Family 30. PNR. NORCD. Two brothers with Persistent Ductus Arteriosus. The younger brother was diagnosed as having a persistent ductus with a large shunt on a continuous murmur when he was only 20 months old. His heart was enlarged (c.t.r. $59 \%$ ) and his blood pressure, $105 / 67 \mathrm{~mm}$. The pulmonary arterial pressure was thought to be high because of the right ventricular hypertrophy but catheterization showed it was normal (19/10) in spite of the large shunt. The ductus was closed successfully when he was 5 years old.

His elder brother had a continuous murmur in life and was proved to have a persistent ductus at necropsy. His death when he was 13 months old was due to meningococcal septicæmia without certain meningitis but probably with bacterial endocarditis. There were no other sibs but the mother had two miscarriages.

**Family 31. Two twin sisters with Persistent Ductus Arteriosus. Two sisters, probably identical twins as they were the same size and difficult to distinguish, both had a persistent ductus closed by Mr. Edge in Sydney in 1943 when they were 7 years old. One unfortunately died after operation, but the other was seen 10 years later and was found to have a normal heart with the ductus satisfactorily closed. We do not know if there were any sibs.

**Family 32. PNR. NORCD. Two sisters with Persistent Ductus Arteriosus. The elder sister had an uncomplicated ductus, which was successfully closed at operation when she was 11 years old. A brother, a year younger, had no abnormality. A sister, 12 years younger, was seen when she was 8 with few symptoms but with a very large heart (c.t.r. 67\%). A systolic murmur had been heard when she was 2 and by the age of 7 there was a murmur in diastole also, regarded sometimes as continuous and sometimes
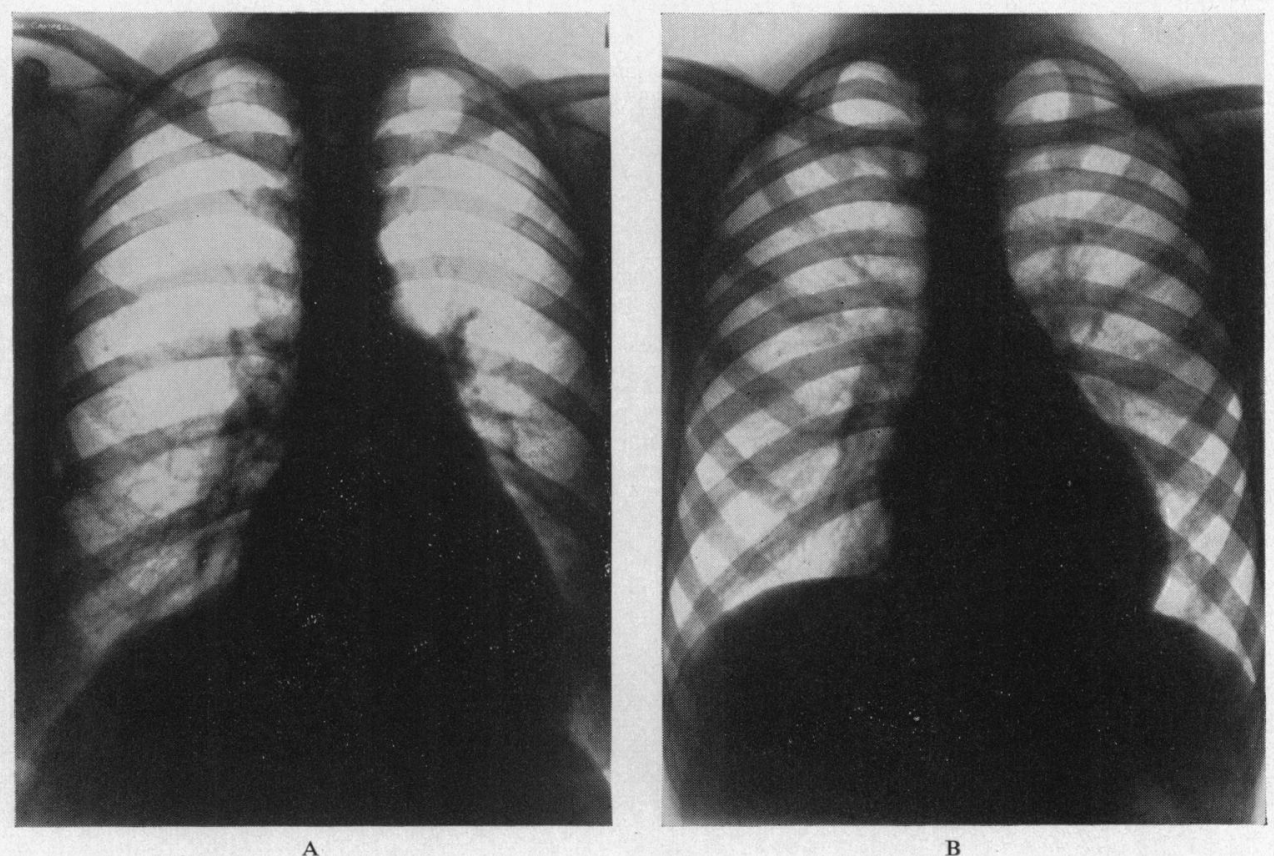

FIG. 1.-Teleradiograms of mother and son $(F 33)$ both with an atrial septal defect, both showing pleonæmic lung fields and a prominent pulmonary arc. (A) From the mother when she was 42 and rather over-weight, with a cardiothoracic ratio of 58 per cent. (B) From the son when he was 13 , showing a heart of normal size, though there was some fullness of the right ventricle. 
as suggestive of pulmonary regurgitation. Catheterization showed the presence of a persistent ductus, pulmonary hypertension $(80 / 50 \mathrm{~mm}$.), and some increase in the oxygen saturation high in the right ventricle, which was probably due to pulmonary regurgitation, though a ventricular septal defect could not be excluded. Operation for her ductus was advised but so far has not been accepted.

**Family 33. PNR. NORCD. Son and mother with Atrial Septal Defect. This is an interesting pair because many features including the shape of the hearts (Fig. 1) and the electrocardiograms (Fig. 2) were so similar. There was little change during six years observation. The son, aged 13, had a systolic murmur and thrill and a short diastolic murmur in the third left space, and fixed splitting of the pulmonary second sound. There was no general enlargement of the heart but on radioscopy some fullness of the right ventricle and a hilar dance with striking pulsation to the periphery. His cardiogram showed secondary $\mathrm{R}$ waves in V1 and some T inversion in V1 and less so in V2. He had few symptoms. Six years later he was persuaded to have catheterization which confirmed the diagnosis with a shunt of 7 litres a minute and a normal pulmonary arterial pressure. The defect, 7 by $4 \mathrm{~cm}$., has now been closed. His elder brother, the only sib, was normal.

His mother, aged 42, had known about her heart since the age of 5 and had not played games at school, but by the age of 16 she did most of what she wanted including dancing, though she could never climb hills well. After she was 30 she could do rather less, but noticed no subsequent change, certainly no more than could be expected from an increase of two stones in weight. Her heart was enlarged (cardiothoracic ratio $58 \%$ ) and there was a nilar dance and pulsation to the mid-zone. The physical signs were the same as those of her son and her cardiogram was very similar though the secondary R waves in V1 were broader and the complexes from V3 to V6 smaller and more notched. Her father had died when 67 with pneumonia, and her mother when 52 with cancer of the stomach.

*Family 34. Child and mother and grandmother, all with Atrial Septal Defect. A girl, aged 7, easily got pulmonary congestion and was somewhat breathless on running. She had signs of atrial septal defect,

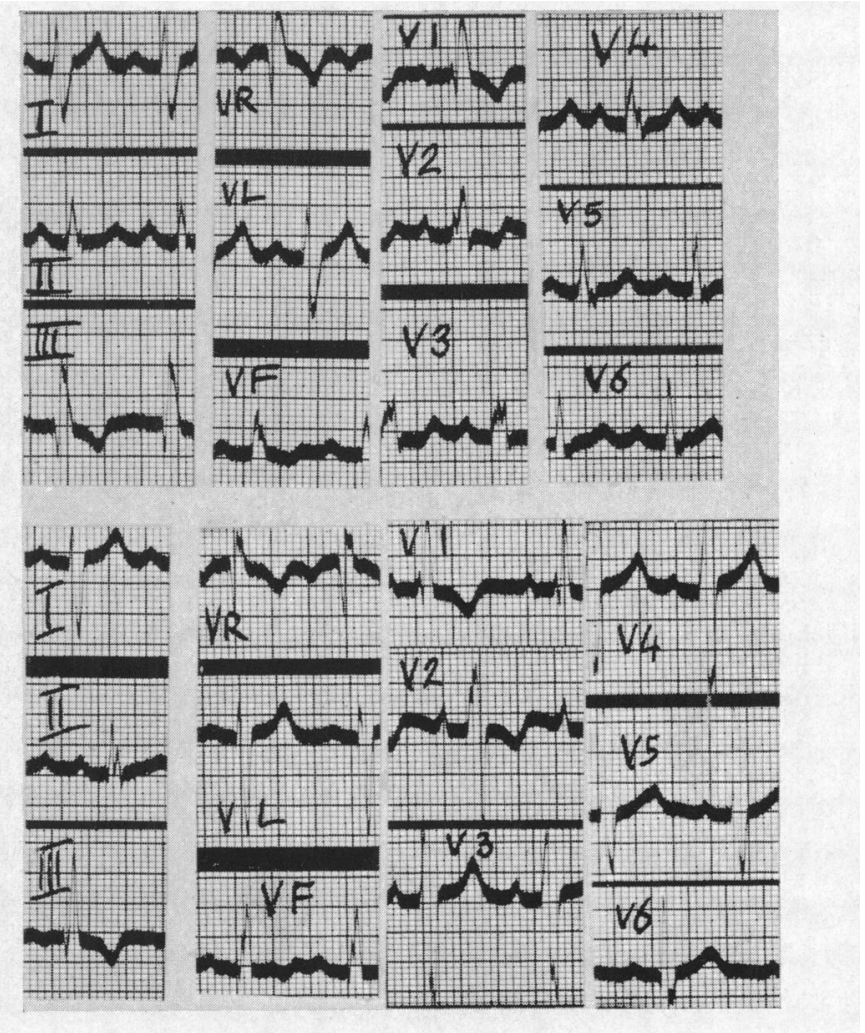

FIG. 2.-Electrocardiograms from the mother and son, both with atrial septal defects (F33); mother above and son below. There is little difference in spite of the mother's age and larger heart: the degree of right ventricular hypertrophy appears to be very similar. 
including a hilar dance, but only moderate enlargement of the right side of the heart. The number of sibs is not known.

Her mother, aged 37, had a systolic murmur that had been present from infancy and other signs of an atrial septal defect with much more enlargement of the right side of the heart and of the pulmonary arteries, and a hilar dance. Investigations were refused. Her mother had died with heart failure when she was 38 and necropsy showed an atrial septal defect. I am indebted to Dr. Breakey for letting me see two of these patients.

**Family 35. Boy with V.S.D. and one or two sisters with C.D.H. A boy, aged 7, had a ventricular septal defect with a pulmonary flow of 22 litres a minute. This was successfully closed by Sir Russell Brock. He was the fifth of 9 children ( 4 girls, 5 boys). The eldest sister was said to have died with whooping cough and a congenital heart lesion (?V.S.D.) when 10 years old, and the youngest, aged 9 months, was thought to have a congenital heart lesion. The other six were all normal.

Pairs thought to have Small Ventricular Septal Defects (V.S.D.) but Unproven (5 Families)

Family 36. PNR. Mother and son with small V.S.D. A girl, aged 17, had known about her heart murmur since the age of 3 , and had been a little breathless when playing tennis. There was a systolic murmur and thrill in the third and fourth left intercostal spaces. Five years later, her condition and her physical signs were unchanged. She then brought up her son, aged 2, with almost identical findings. He had no symptoms but had a rough systolic murmur and a fine thrill in the third and fourth left intercostal spaces. Neither had any general enlargement of the heart but some fullness of both ventricles on radioscopy. Both were thought to have a small ventricular septal defect and the normal lung fields excluded a large shunt.

Family 37. PNR. NORCD. Son and mother with small V.S.D. The son, aged 10, had no symptoms and the murmur had been found at birth. It was heard down the left side of the sternum and a thrill could be felt after exercise. The heart was not enlarged and the lung fields were normal, possibly with a slightly increased blood flow. The cardiogram was normal but four years later showed some left ventricular preponderance. His mother had a rather harsher murmur and a soft thrill at the same site with a normal-sized heart and a normal cardiogram. Her second son, the only sib, was normal. Her father who had been refused life assurance because of a murmur, died when he was 81 , with cardiac infarction, and her brother was said to have a similar murmur.

Family 38. Two twin sisters with small V.S.D. These two were almost certainly identical twins. They had very similar systolic murmurs and curiously parallel histories of various illnesses throughout their lives. For example, both developed corneal scarring after whooping cough, and both developed a femoral hernia during a pregnancy when they were 30 years old. They have been fully reported (Campbell, 1944), but it has not been possible to trace them for re-examination. Nothing else is known about the family.

Family 39. PNR. NORCD. Two brothers with small V.S.D. One of these and sister with Hare Lip. These two brothers, aged 6 and 3, both had rather musical murmurs in the fourth left interspace. In the elder the lungs seemed slightly pleonæmic, but in the younger they were within normal limits, and neither

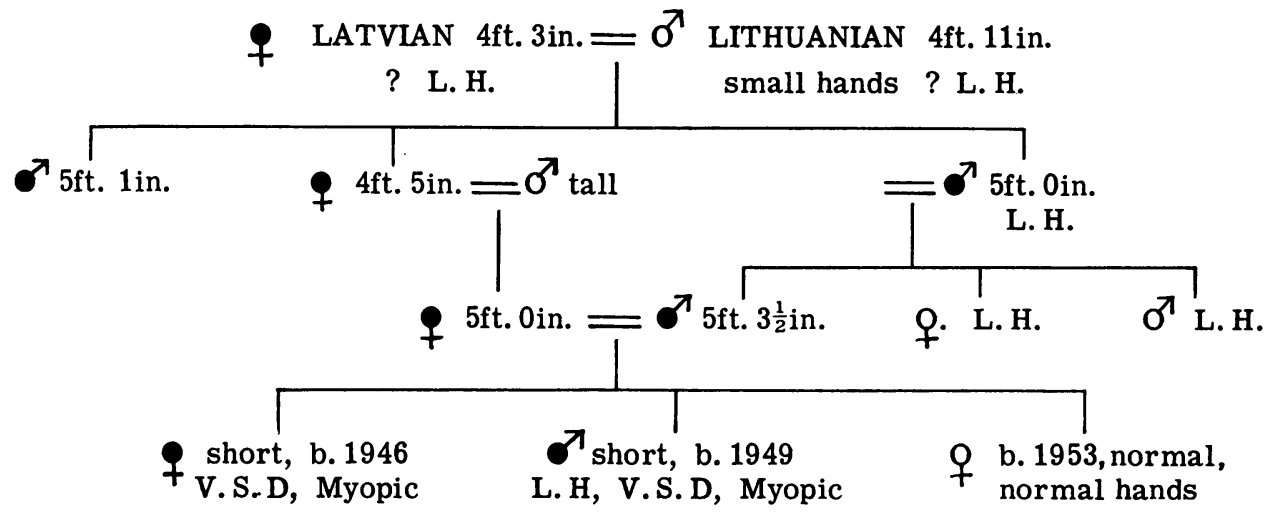

$$
\text { f or } \boldsymbol{\gamma}=\text { short broad hands. } \quad \text { L. H. = Left-handed. }
$$

Fig. 3.-Family tree of a brother and sister with small ventricular septal defects. This is included because of the number in the family who were of short stature with short broad hands and feet (F40). 
had any evidence of ventricular preponderance. They have remained well and without symptoms for seven years.

The younger of these two and their only sister, whose heart was normal, both had hare-lips for which they were having surgical treatment. The father's mother had a line from nostril to lip which suggested she had narrowly escaped a hare-lip.

Family 40. Parents first cousins. Two sibs with small V.S.D. Short stature and short broad hands and feet in four generations (Fig. 3). A sister and brother, aged 3 and 1 years when first seen 7 years ago, had rough systolic murmurs maximal in the third left space with a thrill in the elder. They were a little breathless. There was nothing abnormal on radioscopy or in the cardiogram. Both had severe myopia: both were short and had extremely short broad hands and fingers and short broad feet with a high arch. Their younger sister was normal, both as regards her heart and her size and hands. In the remarks that follow all the patients described as having short broad hands had also short broad feet.

The mother (Mrs. C.) was $5 \mathrm{ft}$. in height and had short broad hands; the father, her first cousin, was $5 \mathrm{ft} .3 \frac{1}{2} \mathrm{in}$. and also had short broad hands. The mother of Mrs. C. was $4 \mathrm{ft}$. 5 in. and had short broad hands; her brother, the father of Mr. C., was $5 \mathrm{ft}$. and had short broad hands. These two had one brother who was $5 \mathrm{ft} .1$ in. and had short broad hands.

The parents of these three, the great-grandparents of our two children, were both small: a Lithuanian man $4 \mathrm{ft} .11$ in. in height with rather small hands had married a Latvian woman who was $4 \mathrm{ft} .3 \mathrm{in}$. in height and had short broad hands. The rest of the subjects described were descended from this pair. So far as is known, no one else in the family had any other form of congenital disease of the heart or elsewhere, but left-handedness was common, occurring in about half the subjects.

\section{ANALYSIS OF THESE FAMILIES}

Consanguinity of Parents. In one of the five families with a case of situs inversus, the parents were first cousins (F7). They were not known to be related in the other four, but the mother's parents were first cousins in one of these four (F8).

There was only one family among the other 35 where the parents were first cousins (F40) and in 29 of the 35 special enquiries had revealed no knowledge of any relationship.

Sex of Affected Patients. In the 25 examples where the pair with congenital heart disease were sibs, they were more often two brothers (eight times) or two sisters (seven times) than a brother and sister (six times). In the other four families three sibs were affected: there were two sisters and a brother three times, and a sister and two brothers once. The total numbers showed no sex difference, there being 27 boys and 27 girls.

In the 9 examples where the pair were child and parent, there were five sons and four daughters but eight mothers and only one father. The numbers, however, are small and in two mothers at least the symptoms were so slight that we should probably not have known about them unless they had been examined when they brought up the children. The only father had been successfully operated on for Fallot's tetralogy (F17).

Twins. There were only two pairs of twins in these families. Both were almost certainly identical twins and both pairs had congenital heart disease, one pair persistent ductus (F31) and the other pair small ventricular septal defects (F38). Although one might expect that both identical twins or neither of them would be affected, this is not the general rule (Uchida and Rowe, 1957). The only other mention of twins was that the parents of the mother of two children with situs inversus were first cousins, the children of twins, probably identical twins (F8).

Number and Sex of Healthy Sibs. The families in which these children were born were on the whole small ones, though several may have been incomplete. We have no information about 2 of the 25 families where the pair were sibs but in the other 23 there were only 34 additional children ( 13 boys, 19 girls, and 2 sibs where the sex is not known). As 19 of these 34 children were in three families, the others were very small. Sometimes, of course, the parents may have decided against having more children, because of their misfortune in having two with heart disease, but this is not the main reason, for often the diagnosis had not been made till some years later.

In the 9 families where the pair with congenital heart disease were child and parent and in the 6 where they were less closely related, the numbers of the younger generation were again small. In the 14 families where we have the information there were only 21 normal children-nine boys, six girls, and six sibs where the sex is not known. 
Each group alone is too small to be significant but, taking the three together, there was no evidence of any sex preponderance among the normal brothers and sisters, 22 being boys, 25 being girls, and 8 sibs where the sex is not known to us.

Other Congenital Malformations in these Families. Among 88 children with heart disease, one would not expect to find many other malformations by chance. Apart from several examples of situs inversus as well as other heart lesions, and the two sisters with the bony and ocular features of arachnodactyly as well (F22), there were, however, four major examples and some minor onesmore than would be expected by chance.

Among these 88, there was one with spina bifida and a club foot (F3), one with a malformed ureter (F15), one with bilateral congenital cataract (F23), and one with a hare lip (F39). The minor lesions included extensive melanodermia (F4), a large nævus on the arm that needed removal (F27), intussusception when two years old (F24), and pathological obesity (F25).

Among the 55 sibs with normal hearts there were a sister with hare lip (F39, where the brother with hare lip has already been mentioned) and a brother with congenital pyloric stenosis (F10) perhaps no more than would be expected by chance. Special enquiries about relatives with any other congenital lesions had been made in 33 of these 40 families and these are marked NORCD.

In general, I have found that patients with congenital heart disease have other malformations more often than would be expected by chance, and that these may be of any type, no one variety being specially common or specially linked with any one form of congenital heart disease.

\section{CONCORDANCE OR Discordance OF THESE MALFORMATIONS}

Among the sibs of a patient with cyanotic congenital heart disease, the incidence of a second case is between seven and twenty times as high as would be expected by chance (Polani and Campbell, 1955). In reported cases the two abnormalities are more often of the same or of similar type (concordant) than of different type (discordant), but one can not know whether more cases are reported just because they are concordant.

However, this is true in our unselected series. Of our 40 pairs, 26 were certainly or probably concordant, 8 were partly concordant with some features in common, and only 6 were completely discordant (Table II). There were 8 pairs where both members were cyanotic, 22 where both were acyanotic, and 10 where one was cyanotic and one acyanotic but some of the differences were more apparent than real.

Cyanotic and Mixed Pairs. Several of the cyanotic patients had complex malformations so it is not easy to say whether they were just the same or somewhat similar. Nevertheless, there appears to be a greater chance of a similar malformation occurring in both members of the pair, and this is very evident in the case of situs inversus, though here the second member did not always have morbus cœruleus as well. Some of those with pulmonary stenosis illustrate differences that were apparent rather than complete.

There were 13 pairs where one of the members had Fallot's tetralogy. Of the other 13 members of these pairs, three had Fallot's tetralogy and one had pulmonary atresia with the aorta arising from the left ventricle: five others (F11-15) had some component of Fallot's tetralogy, three having pulmonary stenosis with a closed ventricular septum, one pulmonary stenosis with a left-to-right shunt through a ventricular septal defect, and one a ventricular septal defect without pulmonary stenosis. Against these 9 (and 4 others where both members of the pair had some form of morbus cœruleus) there were only 4 where the second member had a completely different malformation (F16-19). The eighteenth pair both had situs inversus but one had a normal heart otherwise and one had pulmonary atresia (F10).

In summary, 3 pairs were completely concordant and 4 may have been so; 7 were partly concordant, having some but not all features in common; and 4 were completely discordant.

Acyanotic Pairs. These 22 pairs are easier to discuss from this point of view because the malformations were generally simple ones. They were the same in many pairs. Thus, two sisters both had coarctation of the aorta; two pairs of sibs, and a mother and son, all had congenital aortic 
TABLE II

Proportion of Pairs with Heart Defect that is Concordant or Discordant

\begin{tabular}{|c|c|c|c|c|}
\hline & $\begin{array}{l}\text { Defects } \\
\text { certainly } \\
\text { concordant }\end{array}$ & $\begin{array}{c}\text { Defects } \\
\text { probably } \\
\text { concordant }\end{array}$ & $\begin{array}{c}\text { Defects } \\
\text { partly } \\
\text { concordant }\end{array}$ & $\begin{array}{c}\text { Defects } \\
\text { discordant }\end{array}$ \\
\hline $\begin{array}{c}\text { Both of pair } \\
\text { acyanotic } \\
\text { (22 pairs) }\end{array}$ & 11 & 8 & 1 & 2 \\
\hline $\begin{array}{l}\text { One or both } \\
\text { cyanotic } \\
\text { (18 pairs) }\end{array}$ & 3 & 4 & 7 & 4 \\
\hline All cases & & & 8 & 6 \\
\hline
\end{tabular}

stenosis; and two sibs had pulmonary valvular stenosis. Similarly, in those with left-to-right shunts, four pairs of sibs had a persistent ductus, two pairs (a mother and son, and a mother and daughter) all had atrial septal defects, and a boy and probably his two sisters had ventricular septal defects (F35). Though the diagnosis of this lesion was less certain, there were five pairs with similar physical signs that were thought to indicate small ventricular septal defects (F36-40). Finally, a girl had pulmonary stenosis and a ventricular septal defect with a left-to-right shunt, and her brother had similar physical signs but has not been available for catheterization. Two sisters had arachnodactyly and heart disease and this was probably concordant but we do not know its exact nature in one (F22).

Excluding the partly concordant pair where both had situs inversus, one with nothing else and the other with anomalous pulmonary venous drainage (F9), there were 11 concordant pairs where the lesions were almost certainly the same in both members and 8 where this was probable: against this there were only 2 discordant pairs, one where a daughter had coarctation and her mother a small persistent ductus, and the second where the daughter had a persistent ductus and the mother slight pulmonary stenosis.

Both the discordant pairs were in parent and child. Where the malformations were certainly concordant, 8 pairs were sibs and 3 pairs were parent and child. Including those where they were probably concordant, 14 pairs were sibs and 5 were parent and child. This means that where the acyanotic pairs were sibs they were probably concordant in all 14 pairs, but where they were parent and child they were concordant in 5 but discordant in 2 pairs.

Even when two patients have the same malformation, concordance does not always mean that it was of just the same degree. In the families with aortic stenosis, for example, there was sometimes great variation in the severity (see Table I). Thus, of the two pairs of sisters and brothers, one of each was severe and the other was much less so (F24 and 25), but the mother and son both had a relatively mild degree of aortic stenosis (F26).

There were, however, sometimes very striking resemblances; thus the two sisters with coarctation (F23) both had an unusually high blood pressure for their age, and both had very good results from operation, the pressures falling to low normal figures, 115/70 and 115/75, and the left ventricular preponderance disappearing. Again, the two children of first cousins who had Fallot's tetralogy both died suddenly (F5).

Statistical Significance. If these malformations were distributed by chance the findings would be very different. For assuming an equal distribution of these six acyanotic congenital conditions -an assumption that makes the arithmetic easier and is not very inaccurate except that coarctation and aortic stenosis are less common than the other four-one would expect 3.5 of the 21 pairs to be concordant instead of the 11 or probably 19 that were actually found, and 17.5 to be discordant instead of the 2 that were found-contrasting figures that are most unlikely to be found by chance - and the discrepancy would be still greater if the possibility of some cases being cyanotic were taken into account. 
It is more difficult to be sure how much the total incidence of acyanotic congenital heart disease is above what would be expected by chance. By the end of 1952 we had seen 460 cases of acyanotic heart disease and the number is now about 800 . Assuming a family size of 4 in addition to the propositus ( 2 other children and 2 parents) and an incidence of 1.3 per 1000 for all forms of congenital heart disease still living at the age of one year (MacMahon et al., 1953) the population at risk is $3200(800 \times 4)$ and the number expected would be 4.2 cyanotic and acyanotic cases instead of the 22 acyanotic cases actually recorded. This is five times as many as would be expected by chance, and the chance against so many of them being concordant would be much greater.

Taussig (1947) quotes the view that if a malformation occurs in one offspring, there is a 20 per cent chance that there will be some malformation in subsequent sibs and a 2 per cent chance that it will be the same. In my experience the first figure is much too high but the relative chance of the two defects being the same is far greater.

We are not reviewing the many pairs that have been reported by others, but mention two that appear fully concordant. Courter et al. (1948) reported Lutembacher's syndrome in two sisters, aged 21 and 26. Davidsen (1958) reported well-authenticated atrial septal defect in a mother and in two of her eight children, and some abnormality that led to death from congestive heart failure at six years of age in a third child: the others were healthy. He had not been able to find many examples of atrial septal defect in two members of a family and, adding our cases to those he had collected, there were five examples in a parent and child and only two in sibs. This is contrary to our general experience where the pair are more likely to be sibs than a parent and child but the numbers are too small to be significant.

On these figures, I would not like to say that pairs in a family are more likely to occur with one congenital defect than with another. There is only one pair with coarctation (among about 140 cases) and four pairs with a persistent ductus but the latter is more common. Three pairs with aortic stenosis seems a good deal but the numbers are too small to be decisive. However, Jacobson (1958) has seen it so often with aortic stenosis that she now gets up all sibs of a new case as a routine and has seen some multiple examples as well as pairs.

\section{Genetic and Environmental Causes}

The presence of two or more members of a family with similar congenital malformations suggests that the cause is genetic. When two sibs are affected it could, however, be environmental, if some maternal factor interfered with the development of the foetus in utero. When mother and child are affected this is less likely and is possible only if the same uterine environment had been inherited. The fact that the two malformations in a family are often the same or similar makes an environmental cause even less likely, for it is difficult to imagine how this could produce two examples of coarctation or of pulmonary stenosis, though easier to imagine how it might produce two errors of development of some sort.

This may, in fact, occur when the mother had rubella in the second or third month of pregnancy There is no doubt this can produce malformations of the heart and elsewhere. Among our series of 243 patients with Fallot's tetralogy where careful enquiries were made, there were four examples (Campbell, 1949). We have seen two other examples, one of persistent ductus and one of coarctation of the aorta with complete deafness. In this series we have no evidence that it was ever a factor (and where sibs are affected it could hardly be so, unless they were twins). We do not think that it is an important cause numerically. It does, however, raise the question whether other virus infections or unrecognized causes may be important more often than is thought.

It seems unlikely that there are separate genes responsible for all of the many possible congenital malformations, and it is probably an over-simplification to think that there is always a single cause for congenital malformations. Stewart et al. (1958) studying the families of children who died from leukæmia and other neoplasms, found some evidence for multiple causative factors. For example, an undue proportion of the mothers of these children had been exposed to abdominal $\mathrm{X}$-ray examination during the relevant pregnancy-a proportion that was statistically significant. 
Nevertheless, even if it was the effective cause in every case where there had been such exposure, it accounted for only a proportion of children with leukæmia; and many mothers after such an $\mathrm{X}$-ray examination gave birth to normal children.

Record (1958) has summarized his reasons for thinking that environmental factors in utero may be of importance in some congenital malformations, though he agrees that genetic factors are generally more important. He draws attention to the fallacies of retrospective enquiries about the mother's health during the first three months of pregnancy, when she already knows that she has given birth to a child with some malformation.

The frequency with which two congenital heart lesions in a family are of the same nature seems more in favour of a genetic cause. Even so, it may not always be the sole cause of the malformation, but may make it more likely to develop under certain environmental conditions.

\section{GENETIC INHERITANCE}

Relatively little is known about the genetics of congenital heart disease. For example, Herndon in his chapter on cardiovascular disease in Sorsby's Clinical Genetics covers this in three pages, while diseases of the eye need eighteen pages and these contain many family pedigrees with multiple inheritance through three or four generations: this is uncommon with congenital heart disease where the malformation is more often confined to two cases. Herndon (1953) estimates that 65 per cent of the multiple cases occur as a single sibship and only 35 per cent as multiple sibships or in different generations, and my own figures show an even greater preponderance of single sibships. Gänsslen et al. (1940), reviewing all the reported cases, found most of them in two sibs or in a parent and child, but quoted two families where the malformation was found in four generations: in one of these (their Fig. 11, after Yamada) there were 18 examples in four generations.

Among our cases the defect was found most often in sibs and only twice (F26 and F34) in three generations. When the pair were a parent and child, the malformations were nearly as likely to be discordant (F17, 18, 20, and 21) as concordant (F26, 33, 34, 36, and 37), a much higher proportion of discordance than was found in sibs.

Apart from two families (26 and 34), there was, therefore, nothing to suggest inheritance as a Mendelian dominant character. The only family pedigree illustrated here (Fig. 3) was added because two sibs with small ventricular septal defects were found in a family where short stature and short broad hands and feet were inherited, apparently as a dominant character, through four generations.

Outside the field of congenital heart disease, it is easy to find examples covering several generations. Thirty years ago I investigated a family with acholuric jaundice, where 15 members in five generations were affected (Campbell and Warner, 1926) and there was good evidence that the mode of inheritance was dominant. This, however, was masked at first by some cases being latent and recognizable only by tests for blood fragility, which was the dominant character inherited, the jaundice developing sometimes early, sometimes later, and sometimes not at all, partly under the influence of environmental factors. In the case of congenital heart disease, this combination of causes is only possible at an early stage of fœtal development; though persistent ductus and atrial septal defect-at least ostium secundum-are different and could possibly be influenced by the environment at a later stage.

As there is no good evidence that these congenital heart conditions are inherited as dominant characters, the possibility of recessive Mendelian inheritance must be considered. Cockayne (1938) has produced convincing evidence that situs inversus is inherited in this way. (1) First, he found the ratio of affected to normal children was 1 to 1.7 in reliable sibships where all had been examined, and 1 to 2.9 in all the sibships (omitting those who died before they were one year old): the true proportion was somewhere between these two figures. Theoretically, the ratio should be 1 to 3 , but it is less than this, partly because the two parents being heterozygous (and therefore normal), the family can not be recognized unless there are enough children for one of them to be homozygous (and therefore with situs inversus): for this reason many normal children are perforce omitted, 
making the ratio of affected to normal children higher, somewhere between 1 to 1.5 and the theoretical 1 to 3. (2) Secondly, there was a high incidence of first cousin marriages-in 6 of his 53 fraternities. (3) Thirdly, he knew of only two cases where a parent and child were affected. This should be uncommon, for it can only happen if the parent (who must be homozygous) marries someone who carries this gene but is heterozygous and therefore appears normal: the lower the incidence of the gene in the general population the more rarely will this occur. The relative rarity of the gene will also influence the percentage of cousin marriages needed for significance; and the less common the gene, the more cousin marriages can be expected.

These three points will now be considered in relation to the present series. (1) We cannot apply the ratio of affected to normal children since our families were selected because they had two affected children, but in Fallot's tetralogy, coarctation, and persistent ductus, the ratio was 1 to $1 \cdot 7$, 1 to $2 \cdot 3$, and 1 to $1 \cdot 7$ respectively. (2) In one of the five families with situs inversus, the parents were first cousins-an even higher proportion than in Cockayne's series. Among the 25 other families there was, however, only one other where the parents were first cousins (F40). This figure is too small to express as a percentage but it would be three times as high as the figure we found among parents of children with Fallot's tetralogy - a figure that was consistent with, but not decisive of, recessive inheritance (Polani and Campbell, 1955). (3) The proportion with parent and child affected is much less than with two sibs, but is more than would be expected for recessive inheritance unless the gene is fairly widely distributed in the population. We have, however, reason to think that this is so, for the frequency of situs inversus is about one in ten to twenty thousand and some forms of congenital heart disease are much more frequent than this.

In conclusion, we have no decisive evidence of recessive Mendelian inheritance, apart from situs inversus, but the general picture is compatible with this mode of inheritance.

\section{SUMmARY AND CONCLUSIONS}

We have reported 40 families in which there were two or more examples of congenital heart disease. These were in sibs in 26 families and less often in parent and child.

The malformations were the same or similar (concordant) in most of the acyanotic pairs. They tended to be concordant, but much less decisively so, in the cyanotic or mixed pairs. They were concordant more often when they occurred in sibs than when they were in parent and child.

The influence of genetic and environmental factors has been discussed. The former appear to be the more important, but it seems possible that a genetic factor may not always be decisive alone and may become manifest under the influence of some environmental factor.

There is no evidence of dominant Mendelian inheritance in these cases. There is further evidence for Cockayne's view of recessive inheritance in situs inversus. This may be the case in the other malformations discussed: the evidence is much less decisive but appears to be compatible with recessive inheritance.

When there is one child in the family with congenital heart disease, subsequent children show such a malformation more often than would be expected by chance, but the risk of this is not great and should not generally be taken into account in planning the number of children.

\section{ADDENDUM}

Since this was printed, Dr. Hancock has shown me the typescript of a paper by Carlton et al. (1958). They describe three families like those discussed here. In the first a sister had atrial septal defect and her brother had coarctation. In the second, two sisters and the daughter of one of them all had atrial septal defects. In the third, three sisters had atrial septal defects and the daughter of one of them was thought to have a ventricular septal defect with pulmonary stenosis.

They collected 141 cases that had been reported since 1941, taking this as the time when catheterization became used more widely. Even so, the nature of the defects was unspecified in many of the cases, but 41 of the pairs were concordant against 100 that were discordant or with 
one member unspecified. They too thought that their data were compatible with inheritance of these conditions as autosonal recessives genes.

Wood (1958) says that in his experience when there were two examples of congenital heart disease in a family it was nearly always of the same kind.

\section{REFERENCES}

Abbott, M. E. (1927). In Modern Medicine by W. Osler and T. McCrae.

Brown, J. W. (1939). Congenital Heart Disease. John Bale, Ltd., London, p. 28. (1950). Congenital Heart Disease. 2nd ed., Staples Press, London, p. 27.

Campbell, J. M. H., and Warner, E. C. (1926). Quart. J. Med., 19, 333.

Campbell, M. (1944). Guy's Hosp. Gazette, 58, 228.

(1949). Quart. J. Med., N.S., 18, 379.

(1954). Brit. Heart J., 16, 274.

- and MacCarthy, D. (1957). Guy's Hosp. Rep., 106, 18.

Carlton, R. A., Abelman, W. H., and Hancock, E. M. (1958). New England J. Med. To be published, December 1958.

Cockayne, E. A. (1938). Quart. J. Med., 7, 479.

Courter, S. R., Felson, B., and McGuire, J. (1948). Amer. J. med. Sci., 216, 501.

Davidsen, H. G. (1958). Acta med. Scand., 160, 447.

Gänsslen, M., Lambrecht, K., and Werner, M. (1940). In Just's Handbuch der Erbbiologie des Menschen. Vol. IV., p. 198, Springer, Berlin.

Harrison, J. M. (1948). Med. Press, 220, 109.

Herndon, C. N. (1953). In Sorsby's Clinical Genetics, p. 435, Butterworth \& Co., London.

Jacobson, Belle E. (1958). Personal communication.

MacMahon, B., McKeown, T., and Record, R. G. (1953). Brit. Heart J., 15, 121.

Medvie, C. V., and Rösler, H. (1932). Z. klin. Med., 119, 527.

Polani, P. E., and Campbell, M. (1955). Ann. Human Genetics, 19, 209.

Record, R. G. (1958). Proc. Roy. Soc. Med., 51, 147.

Reynolds, G. (1950). Guy's Hosp. Rep., 99, 178.

Sorsby, A. (1953). Clinical Genetics. Butterworth \& Co., London, p. 435.

Stewart, A., Webb, J., and Hewitt, D. (1958). Brit. med. J., 1, 1495.

Taussig, H. B. (1947). Congenital Malformations of the Heart. Commonwealth Fund, New York.

Uchida, Irene A., and Rowe, R. D. (1957). Amer. J. Hum. Gen., 9, 133.

Wood, P. (1958). Brit. Med.J., $2,704$. 